\title{
Materiais educativos de incentivo a doação de sangue: uma revisão bibliográfica
}

\author{
Educationals materials to encourage blood donation: a literature review
}

Materiales educativos para fomentar la donación de sangre: revisión de la literatura

Rebeca Fontenele Pinheiro ${ }^{1}$, Daniel dos Santos Caldas ${ }^{1}$, André Miller Cortêz Lima ${ }^{1}$, Ellen Nayara Silva de Jesus ${ }^{1}$, Maria Clara Coelho Prazeres ${ }^{1}$, Pedro Henrique Baia Graças ${ }^{1}$, Mateus Silva Tavares $^{1}$, Lucas Samuel dos Santos Oliveira ${ }^{2}$, Paula Cristina Rodrigues Frade ${ }^{1,2 *}$.

\section{RESUMO}

Objetivo: Realizar uma revisão da literatura acerca da produção de materiais educativos para o incentivo à doação de sangue. Métodos: Trata-se de revisão integrativa, incluindo as bases de dados Biblioteca Nacional de Medicina dos Estados Unidos (PubMed), Scientific Electronic Library Online (SciELO) e Biblioteca Virtual em Saúde (BVS). Utilizou-se os descritores "campanha de doação de sangue", "doadores de sangue e educação" e "doação de sangue e redes sociais" no período de janeiro de 2016 a julho de 2021. Resultados: O levantamento bibliográfico abrangeu as publicações nacionais e internacionais, sendo 458 trabalhos lidos e 14 artigos selecionados para compor o estudo. Os artigos mostraram que o sucesso das campanhas de doação de sangue está intrinsecamente relacionado a questões de instrução e a um caráter holístico dos conhecimentos repassados ao potencial doador. Sendo os aspectos comportamentais e culturais do candidato à doação, uso de linguagem acessível e diversidade de formatos, os principais pontos destacados na elaboração de materiais educativos relacionados à doação de sangue. Considerações finais: Dada a heterogeneidade dos materiais usados para incentivo às campanhas de doação de sangue, a compilação destas informações pode auxiliar na produção de materiais educativos e no planejamento de campanhas.

Palavras-chave: Doação de sangue, Doadores de sangue, Campanhas de doação de sangue, Redes sociais.

\begin{abstract}
Objectives: To conduct a literature review on the production of educational materials to encourage blood donation. Methods: This is an integrative review, including the United States National Library of Medicine (PubMed), Scientific Electronic Library Online (SciELO) and Virtual Health Library (VHL) databases. The descriptors "blood donation campaign", "blood donors and education" and "blood donation and social networks" were used in the period from January 2016 to July 2021. Results: The bibliographic survey covered national and international, with 458 works read and 14 articles selected to compose the study. The articles showed that the success of blood donation campaigns is intrinsically related to education issues and a holistic nature of the knowledge passed on to the potential donor. Being the behavioral and cultural aspects of the candidate for donation, use of accessible language and diversity of formats, the main points highlighted in the elaboration of educational materials related to blood donation. Final considerations: Given the heterogeneity of the materials used to encourage blood donation campaigns, the compilation of this information can help in the production of educational materials and in the planning of campaigns.
\end{abstract}

Keywords: Blood donation, Blood donors, Blood donation campaigns, Social networking.

1 Universidade do Estado do Pará (UEPA), Belém - PA. *E-mail: paulacrfrade@gmail.com

2 Universidade Federal do Pará (UFPA), Belém - PA.

SUBMETIDO EM: 10/2021 


\section{RESUMEN}

Objetivo: Realizar una revisión de la literatura sobre la producción de materiales educativos para incentivar la donación de sangre. Métodos: Esta es una revisión integradora, que incluye las bases de datos de la Biblioteca Nacional de Medicina de los Estados Unidos (PubMed), la Biblioteca Electrónica Científica en Línea (SciELO) y la Biblioteca Virtual en salud (BVS). Los descriptores "campaña de donación de sangre", " donantes de sangre y educación" y "donación de sangre y redes sociales" fueron utilizados en el período de enero de 2016 a julio de 2021. Resultados: La encuesta bibliográfica abarcó el ámbito nacional e internacional, con 458 trabajos leídos y 14 artículos seleccionados para componer el estudio. Los artículos mostraron que el éxito de las campañas de donación de sangre está intrínsecamente relacionado con cuestiones de educación y una naturaleza holística del conocimiento transmitido al donante potencial. Siendo los aspectos conductuales y culturales del candidato a donación, uso de lenguaje accesible y diversidad de formatos, los principales puntos destacados en la elaboración de materiales educativos relacionados con la donación de sangre. Consideraciones finales: Dada la heterogeneidad de los materiales utilizados para fomentar las campañas de donación de sangre, la recopilación de esta información puede ayudar en la producción de materiales educativos y en la planificación de campañas.

Palabras-clave: Donación de sangre, Donantes de sangre, Campañas de donación de sangre, Red social.

\section{INTRODUÇÃO}

No século XVII, Harvey, médico inglês, descreveu o mecanismo de circulação sanguínea e funcionalidade do coração, feito que marcou o início do período pré-científico da hemoterapia, o qual viabilizou a administração de medicamentos por intermédio de injeções intravenosas, além da transfusão sanguínea que, inicialmente, era realizada com sangue animal (LORDEIRO MAM, et al., 2017; MORAIS APACG, 2021).

Contudo, devido aos fracassos nas práticas transfusionais nesse período, em razão da falta de conhecimento acerca dos grupos sanguíneos, o procedimento foi proibido na Europa até o início da era científica da hemoterapia, que ocorreu em 1818. Já no Brasil, tal avanço só ocorreu em 1920, com o advento dos primeiros serviços hemoterápicos na cidade do Rio de Janeiro (MINISTÉRIO DA SAÚDE, 2013; FRANTZ SRS, 2018; DUPILAR TC, et al., 2018).

$\mathrm{Na}$ contemporaneidade, todo o processo descrito anteriormente reflete sobre o ato de doar sangue, o qual se depara com entraves associados à falta de conhecimento dos doadores, discriminação, carência de campanhas motivacionais e necessidade de aperfeiçoamento das ferramentas tecnológicas (como as redes sociais) para captar novos doadores, o que leva a uma crise nos estoques de sangue nos centros hemoterápicos. Diante disso, é fundamental que estratégias sejam elaboradas com o intuito de mudar esta realidade (MESQUITA NF, et al., 2021; SILVA JBC, et al., 2021).

Neste sentido, a produção de materiais de incentivo é um meio de superar essas dificuldades, uma vez que fomenta uma mudança cultural na população por meio da conscientização, solidariedade, humanização e ajuda mútua (MINISTÉRIO DA SAÚDE, 2015; SILVA ACC e TROVÃO ACGB, 2021). A produção de uma campanha de doação de sangue com materiais adaptados culturalmente incentiva doações e representa uma importante estratégia (MAKIN JK, et al., 2019; KHOMENKO LM, et al., 2020).

Portanto, é notória a eficácia da implementação de ações que visem a captação de doadores de sangue. Assim, a presente revisão bibliográfica objetivou evidenciar estratégias voltadas para a produção de materiais educativos, como forma de incentivo à prática de doar sangue.

\section{MÉTODOS}

Este trabalho trata-se de uma revisão bibliográfica do tipo integrativa de literatura, no qual o levantamento de material foi realizado através de pesquisas em plataformas de busca: Biblioteca Nacional de Medicina dos Estados Unidos (PubMed), Scientific Electronic Library Online (SciELO) e Biblioteca Virtual em Saúde (BVS). 
O levantamento bibliográfico foi realizado no período de junho a agosto de 2021 a partir da utilização dos seguintes descritores: "campanha de doação de sangue", "doadores de sangue e educação", e "doação de sangue e redes sociais"; e seus correspondentes em inglês "blood donation campaign", "blood donor and education" e "blood donation and social media".

Foi estabelecido o período de publicações de janeiro de 2016 a julho de 2021. A princípio, foram encontradas 458 publicações, sendo 175 na base de dados PubMed, 4 na SciELO e 279 na BVS. A partir desta etapa, foi produzido um banco de dados em planilhas eletrônicas com cada um dos descritores, sendo que em cada uma dessas planilhas foram inseridos os seguintes dados: Título da publicação, Ano da publicação, Autores, Língua do texto, Revista, Base de dados e Resumo.

Após esta etapa, foi realizado a leitura de títulos e resumos, a fim de identificar os artigos que atendiam aos critérios de inclusão: texto original (teses, dissertações, relatos, campanhas, estudos e pesquisas) na língua inglesa e/ou portuguesa e abordar produção de materiais educativos para incentivo a doação de sangue. Os critérios de exclusão foram: textos repetidos ou duplicados e artigos fora da temática proposta. Por fim, foi realizada a leitura na íntegra dos artigos selecionados.

\section{RESULTADOS E DISCUSSÃO}

Os trabalhos passaram por um processo de seleção descrito na Figura 1. Inicialmente, foram encontrados 458 artigos, dos quais, após o processo seletivo aplicando os critérios de inclusão e exclusão, foram selecionados 14 para compor esta revisão integrativa. Com a finalidade de compilar os dados dos artigos selecionados, os principais achados foram descritos juntamente com autores, ano de publicação, título e objetivo de cada estudo no Quadro 1.

Figura 1 - Fluxograma do processo de seleção dos artigos pesquisados. O número de artigos em cada etapa está indicado entre parênteses.

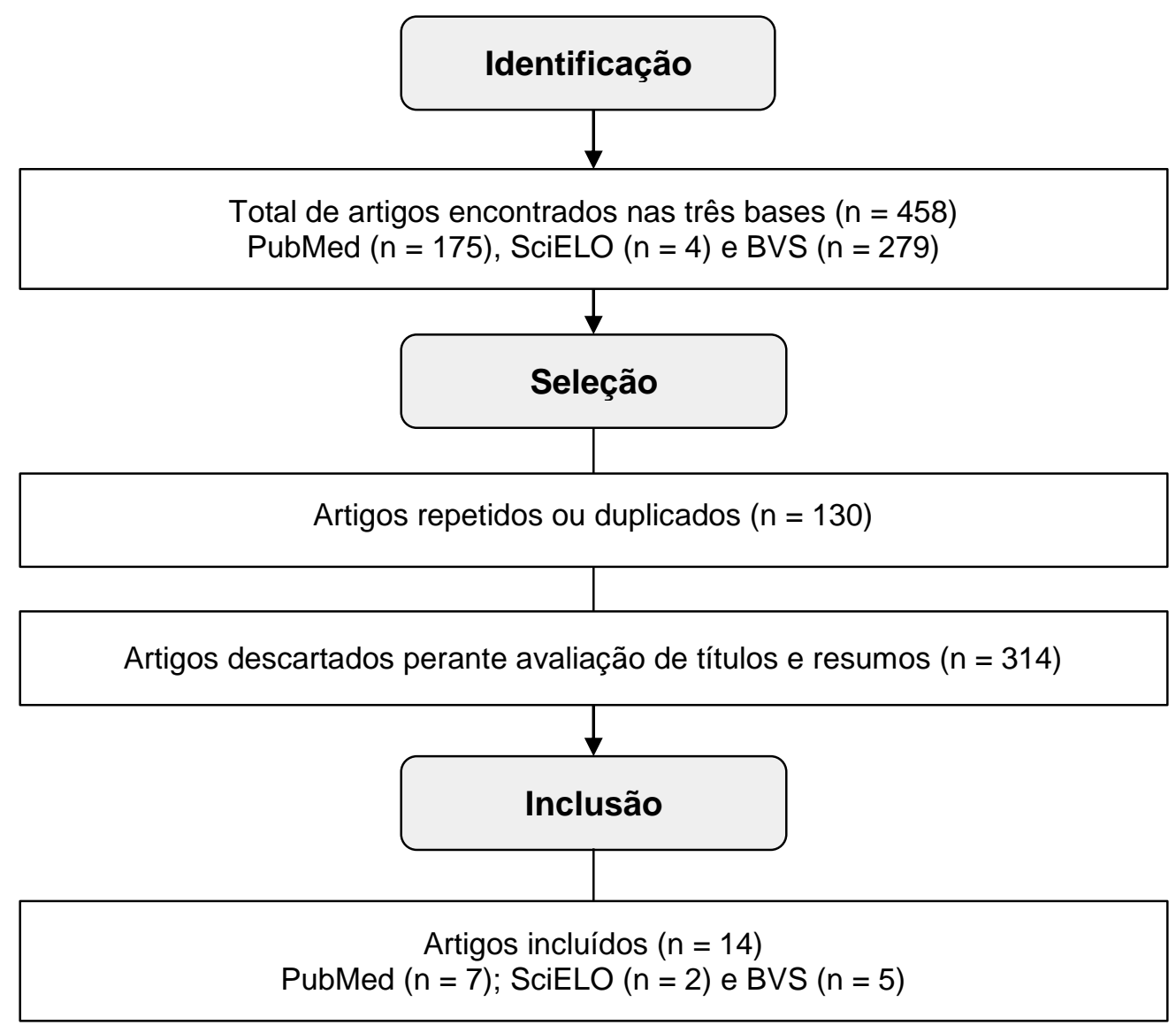

Fonte: Pinheiro RF, et al., 2021 
Quadro 1 - Caracterização dos artigos selecionados na revisão.

\begin{tabular}{|c|c|c|c|c|}
\hline Autor/Ano & Título & Objetivo & Resultados & Conclusão \\
\hline $\begin{array}{l}\text { CARLESSO L, } \\
\text { et al., } \\
2017\end{array}$ & $\begin{array}{l}\text { Estratégias implementadas } \\
\text { em hemocentros para } \\
\text { aumento da doação de } \\
\text { sangue }\end{array}$ & $\begin{array}{l}\text { Verificar a efetividade das estratégias de } \\
\text { marketing social e de acolhimento, antes } \\
\text { e após as ações realizadas, e a demanda } \\
\text { reprimida de sangue } \\
\text { hemocomponentes. }\end{array}$ & $\begin{array}{l}\text { O número de doações em geral aumentou, } \\
\text { principalmente no último mês em que } \\
\text { ocorreram as ações. Todavia, a média de } \\
\text { doações voluntárias de sangue total diminuiu } \\
\text { e de doações voluntárias de plaquetas por } \\
\text { aférese aumentou. }\end{array}$ & $\begin{array}{l}\text { As estratégias implementadas no período do estudo } \\
\text { contribuíram para o aumento no número de } \\
\text { doações de plaquetas por aférese, porém, com } \\
\text { relação à doação de sangue total, apresentou } \\
\text { redução. Assim, ações de captação de doadores de } \\
\text { sangue precisam ser realizadas constantemente. }\end{array}$ \\
\hline $\begin{array}{l}\text { COELHO RP, } \\
\text { et al., } 2016\end{array}$ & $\begin{array}{l}\text { Doar sangue é compartilhar } \\
\text { vida: análise de conteúdo de } \\
\text { aprendizagem de um cartaz } \\
\text { da campanha nacional e } \\
\text { doação de sangue }\end{array}$ & $\begin{array}{l}\text { Realizar a análise do conteúdo de } \\
\text { aprendizagem de um cartaz da } \\
\text { Campanha Nacional de Doação de } \\
\text { Sangue. }\end{array}$ & $\begin{array}{l}\text { O material educativo buscou estimular a } \\
\text { doação de sangue exibindo uma imagem que } \\
\text { faz alusão ao gesto de solidariedade e } \\
\text { gratidão. Conforme a análise realizada, } \\
\text { foram encontrados conteúdos atitudinal e } \\
\text { conceitual, atitudinal e procedimental e } \\
\text { conceitual, atitudinal e factual. }\end{array}$ & $\begin{array}{l}\text { Entender a importância da comunicação nos } \\
\text { processos de ensino-aprendizagem, sendo } \\
\text { necessário agregar à utilização do cartaz outras } \\
\text { formas de sensibilização dos doadores. }\end{array}$ \\
\hline $\begin{array}{l}\text { FRANCIS KL, } \\
\text { et al., } 2017\end{array}$ & $\begin{array}{l}\text { The effects of a culturally- } \\
\text { tailored campaign to increase } \\
\text { blood donation knowledge, } \\
\text { attitudes and intentions } \\
\text { among African migrants in } \\
\text { two Australian States: } \\
\text { Victoria and South Australia }\end{array}$ & $\begin{array}{l}\text { Avaliar o impacto do marketing social em } \\
\text { uma campanha de doação de sangue } \\
\text { entre africanos na Austrália. }\end{array}$ & $\begin{array}{l}\text { Com o aumento da conscientização da } \\
\text { campanha, houve uma maior pontuação no } \\
\text { escore de conhecimento. Ademais, as } \\
\text { pontuações mais positivas na medida de } \\
\text { atitude de doação de sangue foram } \\
\text { associadas ao aumento das intenções de } \\
\text { doação de sangue, autoeficácia e } \\
\text { conscientização. }\end{array}$ & $\begin{array}{l}\text { A campanha adaptada culturalmente foi associada } \\
\text { a uma melhor atitude sobre a doação de sangue, } \\
\text { mas não houve nenhuma mudança de curto prazo } \\
\text { nas intenções de doação de sangue ou no número } \\
\text { de doadores africanos, antes e depois da } \\
\text { intervenção. }\end{array}$ \\
\hline $\begin{array}{l}\text { GOMES FSL, } \\
\text { et al., } 2016\end{array}$ & $\begin{array}{l}\text { Estratégias de captação de } \\
\text { doadores de sangue no } \\
\text { Brasil: Cartilha educativa } \\
\text { para o profissional professor }\end{array}$ & $\begin{array}{l}\text { Desenvolver uma tecnologia educacional } \\
\text { descrita como cartilha, com orientações } \\
\text { para a doação de sangue voltada para o } \\
\text { professor. }\end{array}$ & $\begin{array}{l}\text { Os textos dessa cartilha foram voltados para } \\
\text { os Professores do Ensino Fundamental II e } \\
\text { Médio, pelo fato de os alunos nestes níveis } \\
\text { de ensino estarem próximos da faixa etária } \\
\text { mínima permitida para a doação de sangue. }\end{array}$ & $\begin{array}{l}\text { A cartilha produzida tem sua importância, na } \\
\text { medida que ela pode ser instrumental para a } \\
\text { multiplicação da informação, estimulando a } \\
\text { captação de novos doadores o mais precocemente } \\
\text { possível. }\end{array}$ \\
\hline $\begin{array}{l}\text { HASHEMI S, } \\
\text { et al., } 2019\end{array}$ & $\begin{array}{l}\text { Effective ways to retain first- } \\
\text { time blood donors: a field-trial } \\
\text { study }\end{array}$ & $\begin{array}{l}\text { Analisar a taxa de retorno de doadores de } \\
\text { sangue de primeira vez, de forma a usar } \\
\text { diferentes intervenções para torná-los } \\
\text { doadores regulares. }\end{array}$ & $\begin{array}{l}\text { Constatou-se que, de um universo de } 1356 \\
\text { doadores de sangue, } 394 \text { doaram outra vez } \\
\text { em um período de } 6 \text { meses. Além disso, as } \\
\text { duas intervenções com melhores resultados } \\
\text { foram mensagens emocionais e educativas. }\end{array}$ & $\begin{array}{l}\text { O estudo concluiu que fornecer suporte para os } \\
\text { doadores de primeira vez motiva-os para doarem } \\
\text { novamente. }\end{array}$ \\
\hline $\begin{array}{l}\text { KRANENBUR } \\
\text { G FJ, et al., } \\
2017\end{array}$ & $\begin{array}{l}\text { The effect of World Blood } \\
\text { Donor Day on digital } \\
\text { information seeking and } \\
\text { donor recruitment }\end{array}$ & $\begin{array}{l}\text { Quantificar o impacto do Dia Mundial do } \\
\text { Doador de Sangue na busca de } \\
\text { informações digitais e no recrutamento de } \\
\text { doadores. }\end{array}$ & $\begin{array}{l}\text { No período do estudo, o site da Sanquin foi } \\
\text { visitado } 6.862 \text { vezes ao dia e } 4.293 \text { vezes no } \\
\text { período de controle. Ademais, em junho de } \\
2016 \text {, novos doadores foram registrados em } \\
\text { comparação com o período de controle. }\end{array}$ & $\begin{array}{l}\text { Uma campanha internacional como o Dia Mundial } \\
\text { do Doador de Sangue aumenta a conscientização } \\
\text { sobre a doação de sangue e é eficaz para } \\
\text { convencer as pessoas a se registrarem como } \\
\text { doadores de sangue. }\end{array}$ \\
\hline
\end{tabular}




\begin{tabular}{|c|c|c|c|c|}
\hline Autor/Ano & Título & Objetivo & Resultados & Conclusão \\
\hline $\begin{array}{l}\text { MASSER BM, } \\
\text { et al., 2016a }\end{array}$ & $\begin{array}{l}\text { The impact of the context and } \\
\text { recruitment materials on } \\
\text { nondonors' willingness to } \\
\text { donate blood. }\end{array}$ & $\begin{array}{l}\text { Criar um folheto com abordagens } \\
\text { relacionadas à doação de sangue. }\end{array}$ & $\begin{array}{l}\text { O estudo comprovou que maiores } \\
\text { esclarecimentos nos folhetos informativos } \\
\text { encorajam e incentivam mais pessoas ao ato } \\
\text { de doação de sangue. }\end{array}$ & $\begin{array}{l}\text { O doador em potencial, quando mais esclarecido, } \\
\text { demonstra maior intenção em doar sangue, } \\
\text { considerando um contexto em que a ansiedade em } \\
\text { torno da doação é aumentada. }\end{array}$ \\
\hline $\begin{array}{l}\text { MASSER B, et } \\
\text { al., 2016b }\end{array}$ & $\begin{array}{l}\text { Improving first-time donor } \\
\text { attendance rates through the } \\
\text { use of enhanced donor } \\
\text { preparation materials }\end{array}$ & $\begin{array}{l}\text { Avaliar o impacto de materiais educativos } \\
\text { aprimorados, os quais foram enviados de } \\
\text { forma impressa e por e-mail para } \\
\text { candidatos à primeira doação. }\end{array}$ & $\begin{array}{l}\text { Observou-se um aumento na presença de } \\
\text { doadores, a partir da exposição aos dois } \\
\text { tipos de materiais preparados. }\end{array}$ & $\begin{array}{l}\text { O uso de materiais adaptados para novos doadores } \\
\text { acalma seus ânimos e os prepara para o processo } \\
\text { de doação. }\end{array}$ \\
\hline $\begin{array}{l}\text { SILVA JR, et } \\
\text { al., } 2021\end{array}$ & $\begin{array}{l}\text { Aplicativo de apoio à doação } \\
\text { de sangue: contribuições de } \\
\text { especialistas sobre a } \\
\text { funcionalidade da ferramenta }\end{array}$ & $\begin{array}{l}\text { Avaliar o aplicativo DoeSangue sob uma } \\
\text { perspectiva de especialistas das áreas de } \\
\text { hematologia e hemoterapia. }\end{array}$ & $\begin{array}{l}\text { A ferramenta foi avaliada positivamente, com } \\
\text { Índice de Validação de Conteúdo médio de } \\
0,88 \text {, e teve como pontos positivos a } \\
\text { promoção interativa, engajamento social, e } \\
\text { contribuição para a captação e fidelização de } \\
\text { doadores de sangue. }\end{array}$ & $\begin{array}{l}\text { O aplicativo DoeSangue contribui para a causa, } \\
\text { uma vez que tem significado coletivo, levando } \\
\text { conhecimento e orientação à população com vistas } \\
\text { à promoção da saúde como recurso para a vida. }\end{array}$ \\
\hline $\begin{array}{l}\text { SILVA JR, et } \\
\text { al., } 2018\end{array}$ & $\begin{array}{l}\text { Redes sociais e promoção da } \\
\text { saúde: utilização do facebook } \\
\text { no contexto da doação de } \\
\text { sangue }\end{array}$ & $\begin{array}{l}\text { Analisar a capacidade de mobilização do } \\
\text { Facebook e seu potencial de } \\
\text { engajamento social por meio dos dados } \\
\text { obtidos na FanPage do Centro de } \\
\text { Hematologia Público do Estado do Ceará } \\
\text { - Brasil. }\end{array}$ & $\begin{array}{l}\text { Observou-se que o Facebook do Hemoce } \\
\text { oferece recursos de governança relevantes, } \\
\text { incluindo a identificação das necessidades e } \\
\text { desejos dos usuários. }\end{array}$ & $\begin{array}{l}\text { O Facebook mostrou aplicabilidade no contexto da } \\
\text { doação de sangue, contribuindo para a ampliação } \\
\text { da comunicação com a sociedade e a otimização } \\
\text { de recursos capazes de gerar autonomia do } \\
\text { público. }\end{array}$ \\
\hline $\begin{array}{l}\text { STEPHANOU } \\
\text { AT e } \\
\text { MOREIRA } \\
\text { MC, } 2019 \\
\end{array}$ & $\begin{array}{l}\text { Blood Donors' Perception of } \\
\text { Incentive Campaigns }\end{array}$ & $\begin{array}{l}\text { Analisar a percepção de doadores de } \\
\text { sangue sobre as campanhas de incentivo } \\
\text { à doação. }\end{array}$ & $\begin{array}{l}\text { Os doadores sentem-se mais inclinados a } \\
\text { doar para familiares e amigos e para } \\
\text { campanhas mais abrangentes e emotivas. }\end{array}$ & $\begin{array}{l}\text { As campanhas devem usar as redes sociais como } \\
\text { aliadas na criação de campanhas, além de } \\
\text { promoverem empatia com os participantes. }\end{array}$ \\
\hline $\begin{array}{l}\text { SÜMNIG A, et } \\
\text { al., } 2018\end{array}$ & $\begin{array}{l}\text { The role of social media for } \\
\text { blood donor motivation and } \\
\text { recruitment }\end{array}$ & $\begin{array}{l}\text { Identificar o que mais atrai doadores de } \\
\text { sangue, incluindo doadores de primeira } \\
\text { vez e doadores frequentes. }\end{array}$ & $\begin{array}{l}\text { De } 157 \text { doadores de primeira vez, } 73 \% \\
\text { relataram incentivo de familiares e amigos. } \\
\text { Além disso, dos } 2693 \text { doadores frequentes, } \\
73 \% \text { relataram não precisar de motivação e } \\
7 \% \text { foram motivados por redes sociais. }\end{array}$ & $\begin{array}{l}\text { Família e amigos são o fator mais atrativo para } \\
\text { doadores de primeira vez. Já para doadores } \\
\text { frequentes, as redes sociais são impactantes. }\end{array}$ \\
\hline $\begin{array}{l}\text { TELENTA J, et } \\
\text { al., } 2020\end{array}$ & $\begin{array}{l}\text { Australian lessons for } \\
\text { developing and testing a } \\
\text { culturally inclusive health } \\
\text { promotion campaign }\end{array}$ & $\begin{array}{l}\text { Desenvolver e analisar uma campanha } \\
\text { de doação de sangue voltada para a } \\
\text { comunidade australiano-africana. }\end{array}$ & $\begin{array}{l}\text { De um universo de } 281 \text { participantes, } 75,8 \% \\
\text { sentiram-se incluídos como parte da } \\
\text { comunidade australiana e ficaram mais } \\
\text { inclinados à doação. }\end{array}$ & $\begin{array}{l}\text { O uso de estratégias voltadas para partes } \\
\text { diferentes das comunidades (como a descoberta de } \\
\text { barreiras e preocupações delas) é uma chave para } \\
\text { recrutar mais doadores de sangue. }\end{array}$ \\
\hline $\begin{array}{l}\text { WEHRLI G, et } \\
\text { al., } \\
2020\end{array}$ & $\begin{array}{l}\text { Evaluation and improvement } \\
\text { of blood donor educational } \\
\text { materials: results from a } \\
\text { multicenter randomized } \\
\text { controlled trial }\end{array}$ & $\begin{array}{l}\text { Produzir um novo documento com } \\
\text { abordagens mais amplas e recentes, } \\
\text { apresentando linguagem acessível, } \\
\text { simples e sem jargões médicos, a fim de } \\
\text { evitar prejuízos à compreensão. }\end{array}$ & $\begin{array}{l}\text { Os doadores expostos a esse novo material } \\
\text { apresentaram mais conhecimento acerca } \\
\text { dos procedimentos hemoterápicos. }\end{array}$ & $\begin{array}{l}\text { Os doadores que retornaram tinham um } \\
\text { conhecimento básico maior em comparação com os } \\
\text { novos doadores, devido ao material produzido com } \\
\text { linguagem acessível e compreensiva. }\end{array}$ \\
\hline
\end{tabular}

Fonte: Pinheiro RF, et al., 2021. 
A partir da leitura e da análise das publicações científicas, foi constatado que a produção de materiais educativos para captação de doadores de sangue se baseia principalmente na cultura, no esclarecimento sobre o processo de doação e os sentimentos envolvidos com uso linguagem acessível, nos diferentes formatos (cartaz, cartilha, e-mail, livreto, vídeo, entre outros), nos questionários para se conhecer o perfil do doador local e, mais recentemente, na disseminação de informações por meio de redes sociais.

Sobre a importância da produção de material de incentivo para o aumento do quantitativo de doações de sangue, um estudo realizado nos serviços de hemoterapia públicos do Estado Rio Grande do Sul, no Brasil, preparou, para as pessoas em condições de realizar uma doação, cartilhas informativas sobre os processos da doação de sangue e hemoderivados, cartas, e-mails e ligações telefônicas durante o período de setembro a novembro nos anos de 2014 e 2015 (CARLESSO L, et al., 2017).

Dessa forma, foi feita uma comparação entre todo o período adotado para a implementação das estratégias e notou-se que houve similaridade no número de doadores nos dois primeiros meses de desenvolvimento das ações (setembro e outubro) no ano de 2015 em comparação ao ano de 2014. No mês de novembro, comparando com o mesmo mês do ano anterior, identificou-se que houve um significativo aumento estatístico na quantidade de doações, de 34,56\% para 37,34\%. Ao comparar a média de indivíduos aptos à doação de sangue por mês em cada ano, observou-se que em 2014 foram aproximadamente 820 doadores/mês em 2014 e 860 doadores/mês em 2015 (CARLESSO L, et al., 2017).

A necessidade de produção de materiais e estratégias de captação de doadores também foi observado por Hashemi S, et al. (2019). Neste estudo, foi analisada a taxa de retorno de doadores de sangue de primeira viagem, assente na exposição a diferentes intervenções, objetivando identificar condutas motivacionais eficazes para torná-los doadores regulares. Estes doadores foram divididos aleatoriamente em seis grupos com suporte no último dígito de seu número de doação. Em seguida uma intervenção diferente foi aplicada para cada grupo, as quais eram: chamadas de lembrete, uma carta educacional, uma carta emocional sobre a doação de sangue, uma camiseta brinde ao término da primeira doação e uma participação em uma reunião motivacional após sua primeira doação. O sexto grupo não obteve nenhuma intervenção (HASHEMI S, et al., 2019).

Os resultados indicaram um aumento das taxas de retorno de doadores de primeira vez a partir da aplicação de estratégias de intervenção (29\%), em relação às taxas de retorno após 6 meses sem medidas interventivas (20\%). Além disso, a pesquisa demonstrou que a mensagem emocional foi a estratégia mais eficaz para convencer doadores de sangue de primeira viagem a doar novamente, sendo observado que 0 nível de instrução educacional de cada participante não influenciou no entendimento sobre o processo de doação de sangue (HASHEMI S, et al., 2019).

Neste sentido, percebe-se que estratégias educativas de incentivo à doação são efetivas. A divulgação para o público jovem é importante como forma de encorajar futuros doadores. Como foi verificado no trabalho de Gomes FSL (2016), realizado no Estado do Rio de Janeiro, Brasil. Foi produzida uma cartilha educativa para professores e alunos do Ensino Fundamental e Médio que estavam próximos da faixa etária mínima permitida para a doação de sangue. Dessa forma, a cartilha teve como princípios: incentivos ao professor para que este possa abordar a temática durante suas aulas, reflexões sobre a baixa taxa de doação de sangue no Brasil, questionamentos e caracterização de receptores. A elaboração deste material educativo tem sua importância não só na multiplicação da informação e captação de novos doadores, mas também pela possibilidade de ser um mecanismo de interseção entre saúde e educação (GOMES FSL, et al., 2016).

O acesso à informação a respeito do processo de doação de sangue é fundamental para a busca de novos doadores e de sua fidelização. Um estudo realizado pela Food and Drug Administration (FDA), concluiu que muitos doadores possuem um nível de conhecimento abaixo do esperado e ideal, fato que representa um entrave para o recrutamento de mais indivíduos para a participação na doação de sangue. Tal cenário é consequência da utilização de materiais educacionais que contém informações restritas, as quais não esclarecem muitos aspectos básicos referentes à doação de sangue ou se utilizam de uma linguagem hermética imbuída de jargões e termos técnicos (WEHRLI G, et al., 2020). 
Neste contexto, a pesquisa trabalhou na produção de um novo documento que inclui abordagens mais amplas e recentes. Ademais, o material produzido apresentava linguagem acessível, simples e sem jargões médicos, a fim de evitar prejuízos à compreensão. O novo material foi analisado por meio de questionários e entrevistas com doadores novos e recorrentes e os resultados demonstraram que os doadores expostos a esse novo material apresentaram mais conhecimento acerca dos procedimentos hemoterápicos (WEHRLI G, et al., 2020).

Além disso, é importante compreender o comportamento, os valores e as atitudes do doador de sangue para a produção de materiais educativos. Um estudo feito na França verificou que muitos indivíduos, quando expostos a elementos como imagens de tubo de coleta, têm a ansiedade aumentada, diminuindo a intenção de doar sangue. Diante disso, um novo folheto foi elaborado, porém com abordagens relacionadas à importância da doação, pequenos relatos, informações básicas sobre a doação de sangue, além da explanação de dúvidas e preocupações comuns. Os pesquisadores utilizaram o novo folheto educativo para o recrutamento de 972 não doadores aptos à doação de sangue, em um período de um mês para coleta de dados (MASSER BM, et al., 2016a).

Em seguida, os participantes receberam o novo material elaborado ou o folheto comumente usado e responderam um questionário acerca dos sentimentos relacionados à doação, intenções de doar e competência em lidar com uma reação negativa à doação. Os resultados apontaram que os doadores que leram o novo material mostraram maior intenção em doar do que aqueles que foram expostos ao material comumente utilizado. Assim, a conclusão é que o doador em potencial, quanto mais esclarecido, maior é sua intenção em doar sangue, considerando um contexto em que a ansiedade em torno da doação é aumentada (MASSER BM, et al., 2016a).

Ainda em relação à condição emocional dos doadores de sangue, foi realizada uma pesquisa de campo na França, com um total de 3646 candidatos que haviam agendado sua primeira doação. Os participantes receberam uma cópia impressa ou um link enviado por e-mail com materiais educativos. Os participantes também receberam uma chamada roteirizada de acordo com esses materiais de preparação. Como resultado, foi observado um aumento de $2 \%$ na taxa de comparecimento de doadores, demonstrando a eficácia dessa metodologia (MASSER B, et al., 2016b).

Outro estudo que também aborda esta temática foi realizado na cidade de Ribeirão Preto, Brasil, o qual foi observada a existência de diversas estratégias para a captação de doadores, porém há poucos trabalhos sobre o impacto dessas campanhas no comportamento dos indivíduos. Assim, foi analisada a percepção de doadores a fim de auxiliar no planejamento de campanhas de doação. Utilizaram questionários de dados sociodemográficos e entrevistas gravadas em áudio digital. Posteriormente, a análise de dados foi feita em quatro etapas: a familiarização com os dados adquiridos e estudos feitos com base na literatura, leitura do material produzido sem critérios rígidos, codificação do texto em unidades específicas e por fim categorização das unidades considerando os objetivos do estudo (STEPHANOU AT e MOREIRA MC, 2019).

Os resultados mostraram que os participantes têm maior incentivo em campanhas de amigos e familiares, o que facilita o vínculo social e a fidelidade do doador. Outro fator de incentivo foi o comportamento de doação com base no desejo de ser ajudado, já que no futuro qualquer indivíduo pode precisar da transfusão sanguínea. Ademais, as mídias sociais receberam destaque como ferramentas importantes, e os entrevistados sugeriram um maior apelo emocional nas publicações, além da primeira experiência de doação ser de extrema importância, pois o indivíduo que reagiu de forma positiva tende a se tornar um doador regular (STEPHANOU AT e MOREIRA MC, 2019).

Os aspectos culturais representam outro ponto importante a ser levado em consideração para o sucesso na produção de materiais educativos relacionados à doação. Francis KL, et al. (2017) realizaram um estudo que objetivou avaliar o impacto do uso de materiais direcionados e culturalmente sensíveis em dois estados australianos, sendo o público-alvo a comunidade composta por imigrantes africanos. A pesquisa analisou que há muitas barreiras no que tange à participação desse público na prática da doação de sangue entre as quais destacam-se: falta de confiança nas organizações biomédicas de saúde, pouco conhecimento a respeito da doação de sangue, discriminação percebida e falha na adaptação das mensagens de saúde que ocasionam prejuízos à comunicação. 
Nesse contexto, foi realizada uma campanha de comunicação que incluiu os seguintes materiais: um livreto (impresso, online e USB), quatro cartazes diferentes e um pequeno vídeo. Os materiais estavam disponíveis nos idiomas inglês, suailí, árabe e kirundi. Ademais, estes foram submetidos a vários pré-testes envolvendo a comunidade-alvo a fim de garantir o entendimento do conteúdo proposto. Nesse sentido, a campanha culturalmente inclusiva, bem como os materiais relacionados foram associados a uma melhora no conhecimento e atitudes acerca da doação de sangue, evidenciando os benefícios adquiridos pela realização de uma campanha direcionada à cultura (FRANCIS KL, et al., 2017).

O mesmo foi observado em um trabalho realizado com outra comunidade australiano-africana. Sete grupos foram conduzidos com 62 membros da comunidade imigrante da África Subsaariana de áreas em Sydney e Illawarra, em New South Wales e Austrália, cada grupo teve sua testagem realizada em um ambiente comunitário, como um salão comunitário ou centro de saúde. Foram mostrados materiais nos idiomas inglês, árabe, suaíli e kirundi. Todos os participantes tiveram acesso à informação por meio de pôster, livreto informativo e vídeo, todos incorporando imagens, citações e vozes de pessoas da comunidade africana. Com isso, a pesquisa demonstrou que, aproximadamente, $78 \%$ dos estudados sentiram-se parte da comunidade australiana após serem expostos aos materiais, o que fortaleceu a ideia de superação de barreiras discriminatórias e igualdade, incentivando o ato de doação de sangue como uma forma de inclusão àquele povo (TELENTA J, et al., 2020).

A produção de materiais educativos em diferentes formatos também é um ponto em destaque para alcançar maior público. Um trabalho feito no estado do Mato Grosso do Sul, Brasil, analisou um cartaz produzido pelo Ministério da Saúde para a Campanha Nacional de Sangue, que ocorre anualmente. Foi feita uma pesquisa documental, onde o conteúdo de aprendizagem foi apresentado em forma de tabela dividida em conteúdo, tipologia e justificativa. Concluiu-se que os materiais impressos e outros recursos audiovisuais são fontes de informações importantes, capazes de estabelecer a comunicação entre as partes e influenciar no comportamento dos indivíduos. Portanto, o material foi capaz de sensibilizar o público-alvo e incentivá-lo à doação (COELHO RP, et al., 2016).

Adicionalmente, as ferramentas virtuais são essenciais para a divulgação de materiais educativos e para o planejamento de campanhas de doação de sangue na atualidade. Abordando esta questão foi realizado um estudo, em Fortaleza, Ceará, Brasil, acerca da análise, por especialistas, das funcionalidades do aplicativo "DoeSangue". Concluiu-se que foi extremamente relevante a criação desta ferramenta virtual, pois possui uma compilação de informações que cativa doadores, no sentido de esclarecer dúvidas sobre o processo de doar, contudo ainda parece carecer de uma linguagem mais acessível ao público. Assim, bonificações não monetárias foram pontos positivos dele, bem como sua construção intuitiva, para incentivar o altruísmo dos doadores. Dessa forma, o desenvolvimento de estratégias online é um grande aliado no incentivo à doação de sangue (SILVA JR, et al., 2021).

Outra pesquisa realizada nesta temática, concluiu que o uso das mídias sociais, com destaque para a ferramenta Facebook, contribui para aquisição de conhecimento referente à doação, uma vez que o acesso à informação sobre o assunto é um dos fatores motivacionais para a participação no ato de doar. Dessa forma, a divulgação de conteúdos como critérios para a doação, relatos de pessoas que já doaram e elucidação de dúvidas e preocupações, auxilia na redução do medo de doar e se mostra como estratégia vantajosa para a captação de doadores. Neste contexto, os resultados do estudo apontam que o Facebook pode ser utilizado como uma prática de promoção da saúde, haja vista que permite comunicação com o meio social, permitindo maior visibilidade e engajamento à causa da doação de sangue (SILVA JR, et al., 2018).

Outra uma ferramenta virtual que pode ser utilizada é o "Google Trends". Um trabalho realizado com objetivo de verificar o engajamento de doadores de sangue (na Holanda, principalmente) por informações sobre doação no Dia Mundial do Doador de Sangue, identificou um aumento de visitantes no site da Sanquin (instituição de hemoterapia holandesa) em $50 \%$ nas 3 semanas que foram analisadas. Também foi observado um aumento do uso das redes sociais por parte dos candidatos a doação em campanhas abrangentes, mostrando a necessidade da criação de acervos de informações confiáveis para que eles sejam mais encorajados a doar sangue (KRANENBURG FJ, et al., 2017). 
Ademais, um estudo feito com um total de 2.920 participantes (majoritariamente da Alemanha), constatou que $7,4 \%$ foram motivados por redes sociais, mostrando que esse meio de incentivo foi significante e ainda mostrou que, aproximadamente, $70 \%$ dos usuários de redes sociais participantes possuem menos de 30 anos, ou seja, o potencial de recrutamento de jovens doadores por esse meio é muito grande. Além disso, $26 \%$ foram motivados por amigos/parentes, mostrando a eficácia dessa estratégia, a qual deve continuar a ser incentivada (SÜMNIG A, et al., 2018).

Por fim, o levantamento demonstra que hemocentros e instituições relacionadas aos processos de doação de sangue são responsáveis pela educação de doadores em potenciais, por intermédio da elaboração de materiais educativos. O número de publicações revela a necessidade de maior divulgação do processo de elaboração de materiais educativos. Demonstraram também que as redes sociais são impactantes na captação de doadores, principalmente os mais jovens, sendo necessário mais investimento nesse tipo de estratégia. Neste contexto, o acesso à instrução e ao conhecimento constituem as bases para a prática da doação, atraindo doadores cientes sobre a importância da doação, além de garantir a obtenção de hemocomponentes e hemoderivados de maneira segura ao doador e ao receptor.

\section{CONSIDERAÇÕES FINAIS}

É seguro afirmar que a elaboração de materiais destinados a aprimorar a captação de doadores é uma temática a ser discutida constantemente, considerando-se a heterogeneidade das variáveis sociais e humanas envolvidas na questão. Foram encontrados diversos materiais educativos e formas de utilização dos meios de comunicação para captar e manter os doadores nos sistemas de hemoterapia. Portanto, o presente estudo pode ser utilizado como material de suporte para a elaboração de estratégias e materiais educativos voltados para campanhas de doação de sangue, já que apresenta um agregado de métodos eficientes que podem otimizar e aprimorar a captação de doadores.

\section{REFERÊNCIAS}

1. CARLESSO L, et al. Estratégias implementadas em hemocentros para aumento da doação de sangue. Revista Brasileira em Promoção da Saúde, 2017; 30(2).

2. COELHO RP, et al. Doar sangue é compartilhar vida: análise de conteúdo de aprendizagem de um cartaz da campanha nacional e doação de sangue. Revista Saúde Pública Mato Grosso Sul, 2016; 22-27.

3. DUPILAR TC, et al. Captação de doadores de sangue: da era científica mundial à era da informação digital. Serviço Social e Saúde, Campinas, SP, 2018; 17(1): 95-126.

4. FRANCIS KL, et al. The effects of a culturally-tailored campaign to increase blood donation knowledge, attitudes and intentions among African migrants in two Australian States: Victoria and South Australia. Plos one, 2017; 12(11): e0188765.

5. FRANTZ SRS. O processo de trabalho dos enfermeiros no serviço de hemoterapia: entre o prescrito e o real. Tese (Doutorado em Enfermagem) - Programa de Pós-graduação em Enfermagem. Universidade Federal de Santa Catarina, Florianópolis, 2018; 165p.

6. GOMES FSL. Estratégias de captação de doadores de sangue no Brasil: Cartilha educativa para o profissional professor. Relatório final do Mestrado Profissional - Programa de Pós-Graduação em Saúde e Tecnologia no Espaço Hospitalar (PPGSTEH), Universidade Federal do Estado do Rio de Janeiro, Rio de Janeiro, 2016; 119 p.

7. HASHEMI S, et al. Effective ways to retain first-time blood donors: a field-trial study. Transfusion, 2019; 59(9): 28932898.

8. KHOMENKO LM et al. Analysis Of The Marketing Activities In The Blood Service: Bibliometric Analysis, 2020.

9. KRANENBURG FJ, et al. The effect of World Blood Donor Day on digital information seeking and donor recruitment. Transfusion, 2017; 57(10): 2458-2462.

10. LORDEIRO MAM, et al. Evolução da história de doação de sangue no Brasil dentro do âmbito do SUS. Revista Rede de Cuidados em Saúde, 2017; 11(3).

11. MAKIN JK, et al. Interventions to increase blood donation among ethnic/racial minorities: a systematic review. Journal of environmental and public health, v. 2019, 2019.

12. MASSER BM, et al. The impact of the context and recruitment materials on nondonors' willingness to donate blood. Transfusion, 2016a; 56(12): 2995-3003.

13. MASSER B, et al. Improving first-time donor attendance rates through the use of enhanced donor preparation materials. Transfusion, 2016b; 1628-1635. 
14. MESQUITA NF, et al. Dificuldades e estratégias relacionadas com a doação de sangue em um serviço de hemoterapia. Revista RENE: Revista da Rede de Enfermagem do Nordeste, 2021; 22: 1-9 e70830.

15. MINISTÉRIO DA SAÚDE. Técnico em Hemoterapia: Livro Texto. 2013. Disponível em: https://bvsms.saude.gov.br/bvs/publicacoes/tecnico_hemoterapia_livro_texto.pdf. Acesso em: 10 de julho de 2021.

16. MINISTÉRIO DA SAÚDE. Manual de Orientações para Promoção da Doação Voluntária de Sangue. 2015. Disponível em: https://bvsms.saude.gov.br/bvs/publicacoes/manual_orientacoes_promocao_doacao_voluntaria_sangue.pdf. Acesso em: 30 de julho de 2021.

17. MORAIS APACG. Hemoterapia na saúde pública do Estado de Goiás 1999-2018. Dissertação (Mestrado em Saúde Coletiva) - Mestrado Profissional Convênio Universidade Federal de Goiás e Núcleo de Estudos em Saúde Coletiva (UFG/NESC), Goiânia, 2021; 121 p.

18. SILVA ACC, TROVÃO ACGB. Leucorredução como prevenção de reações transfusionais: uma revisão da literatura. Revista Eletrônica Acervo Saúde, 2021; 13(5): 7173-7173.

19. SILVA JBC, et al. Campanha de doação de sangue realizada por discentes de biomedicina: um relato de experiência. Revista Eletrônica Acervo Saúde, 2021; 13(9): 8752.

20. SILVA JR, et al. Aplicativo de apoio à doação de sangue: contribuições de especialistas sobre a funcionalidade da ferramenta. Ciência \& Saúde Coletiva, 2021; 26: 493-503.

21. SILVA JR da, et al. Redes sociais e promoção da saúde: utilização do facebook no contexto da doação de sangue. Revista Ibérica de Sistemas e Tecnologias de Informação (RISTI), 2018; 30: 107-122.

22. STEPHANOU AT, MOREIRA MC. Blood Donors' Perception of Incentive Campaigns. Paidéia (Ribeirão Preto), 2019; 29.

23. SÜMNIG A, et al. The role of social media for blood donor motivation and recruitment. Transfusion, 2018; 58(10): 22572259.

24. TELENTA J, et al. Australian lessons for developing and testing a culturally inclusive health promotion campaign. Health promotion international, 2010; 35: 217-231.

25. WEHRLI G, et al. Evaluation and improvement of blood donor educational materials: results from a multicenter randomized controlled trial. Transfusion, 2020; 60(8): 1756-1764. 